\title{
Announcement
}

\section{Database '83}

The Hungarian National Technical Information Centre and Library announces the celebration of the centenary of its establishment in June 1983.

On this occasion, an International Conference on the Use of Internationally Available Databases in Scientific and Technical Information Systems will be organised in cooperation with UNESCO and interested Hungarian bodies, with participation of international governmental and non-governmental organisations. The conference will take place on 6-8 June, 1983, in Budapest.

\section{Main topics of the conference}

1. Internationally available databases and criteria for their selection by national systems

What, in what form, and under what conditions, is available on the international market of databases? How to harmonise information services based on national language information processing and/or on internationally available databases? Criteria for subject-coverage, compatibility, legal and financial conditions etc., upon which national systems could decide on the use of databases. How to coordinate the use of databases produced by international work sharing information systems, and those produced by private or public enterprises at national level? Who has to decide on the choice, acquisition and use of databases?

\section{Organisation and management of the use of databases in national systems}

The degree of centralisation and/or decentralisation in the application of databases to national systems and in the connected information services and financing. Systems and services for distributing the output of databases. How to harmonise the role of information services based on document-, discipline- and problem-oriented databases? How to satisfy the increased demand for primary documents? Organisational, technical and financial aspects.

0167-5265/82/0000-0000/\$02.75 @ 1982 North-Holland 


\section{The impact of new information and documentation technology}

Present and future information techniques for various kinds of users. Databases on microform: their specific features and interrelation with computer-readable databases. On-line and off-line access: alternative or complementary methods? How to achieve technological and methodological compatibility between networks and sub-networks? Financial aspects of the various data transmission technologies; trends of development and influence on information services. The impact of modern text transmission and display (teletext etc.) on the use of databases and on the availability of primary documents and data. Development trends of the interconnected use of computers and micrographics in database applications.

\section{The interaction of user habits and database use}

Influence of the expanded use of databases on user needs and habits. User requirements for the choice, use and organisation of databases and the availability of original documents and data. How can databases and joint information services back complex management information systems? How to reduce users' aversion to new forms and techniques of information services. The changing role of information specialists and intermediaries; how to train them to meet changing requirements?

\section{General information}

Invited participants (decision-makers, systems analysts, information specialists, librarians, etc.) come from various organisations:

- Intergovernmental organisations promoting the development of scientific and technical information systems (organisations of the United Nations system: UNIDO, UNESCO, IAEA, FAO etc.; CMEA, OECD, Commission of the European Communities etc.), as well as international information systems established and supported by the above organisations (e.g. INIS, AGRIS, INFOTERRA, ISDS, ISTIS, DIANE etc.).

- Non-governmental professional organisations interested in scientific and technical information (FID, IFLA, ISO, EUSIDIC etc.).

- Producers of internationally available databases (CAS, EI, INSPEC, ISI etc.), as well as information dissemination centres (ESA, Lockheed, SDC etc.).

- Information transmission systems (Tymnet, Telenet, Euronet, Radio Austria, Radio Switzerland etc.).

- National bodies, committees, professional organisations involved in management of national scientific and technical information policy and/or in designing and organising national information systems.

- Information and documentation centres, national, research-, university- and special libraries.

The expected number of participants is about one hundred, i.e. about seventy 
experts from the industrialised and developing countries and about thirty specialists from Hungary.

\section{Exhibition}

During the Conference a small exhibition of publications, samples of information services, demonstrative materials, learning kits etc., related to the topics dealt with at the Conference, shall be organised.

Relevant materials are requested.

\section{Film and video show}

In order to give comprehensive illustration of information technologies, methods, media, organisations, systems, networks and services, a film and video show shall organised during the Conference.

Relevant materials are requested.

\section{Further details}

The conference fee will be US $\$ 100$. In addition to the programme of sessions this includes the abstracts and full text of papers (to be distributed among the participants on the site), the proceedings, free entrance to the exhibition and the film and video show, as well as refreshments and social events.

The languages of the conference shall be English, French and Russian. Simultaneous interpretation shall be provided.

For additional information, please contact: Organising Committee, Database '83, c/o the National Technical Information Centre \& Library, P.O. Box 12, H-1428 Budapest, Hungary. 